Article

\title{
The Processes of Inclusion and Exclusion in Physical Education: A Social-Relational Perspective
}

\author{
Mette Munk ${ }^{1,2, *}$ and Sine Agergaard ${ }^{1}$ \\ ${ }^{1}$ Section of Sports Science, Department of Public Health, University of Aarhus, 8000 Aarhus, Denmark; \\ E-Mails: mmj@ph.au.dk (M.M.), sa@ph.au.dk (S.A.) \\ ${ }^{2}$ University College Syddanmark, 6100 Haderslev, Denmark \\ * Corresponding author
}

Submitted: 27 October 2014 | In Revised Form: 2 February 2015 | Accepted: 12 March 2015 |

Published: 25 June 2015

\begin{abstract}
Existing research on inclusion and exclusion processes in physical education (PE) has particularly focused on exclusion from PE as something being done to students and attributed to specific social categories such as (female) gender, (low) physical skills or (minority) ethnic background. This article aims to develop a social-relational perspective on inclusion and exclusion processes defined as students' participation or non-participation in PE interpreted as a community of practice. In so doing, the article examines how students' experiences of participation and non-participation in PE are influenced by complex interactions within the group of students and in negotiations with teachers about the values and practices of PE. The article is based on an embedded single-case study carried out over the course of 6 months through weekly observations of PE classes in a multi-ethnic school, as well as focus group interviews with students and teachers. Using Etienne Wenger's conceptual tools, we show that a student's degree of participation in the community of practice of PE-classes is closely related to the legitimacy of the student and the extent to which the student experiences PE as meaningful. Some students were excluded from PE because they did not have the physical skills and social relations necessary to gain legitimacy from other students. Others chose not to participate because PE was not meaningful to them. This latter type of non-participation from students who experienced lacking meaningfulness was evident in PE classes that had little transfer value and limited prospect for students to develop the knowledge, skills or the understanding necessary to move towards full participation in the classes. Thus, the article argues that an understanding of the variety in students' participation or non-participation is important not only in terms of how we talk about students as passive victims or active agents, but also in terms of future intervention aimed at promoting inclusion processes in PE.
\end{abstract}

\section{Keywords}

inclusion; exclusion; meaningfulness; legitimacy; legitimate peripheral participation; situated learning; physical education; sport

Issue

This article is part of the special issue "Sport for Social Inclusion: Critical Analyses and Future Challenges", edited by Dr. Reinhard Haudenhuyse (Vrije Universiteit Brussel, Belgium) and Professor Marc Theeboom (Vrije Universiteit Brussel, Belgium).

(C) 2015 by the authors; licensee Cogitatio (Lisbon, Portugal). This article is licensed under a Creative Commons Attribution 4.0 International License (CC BY).

\section{Introduction}

For many years there have been indications that not all students experience inclusion in physical education
(PE), both in Denmark (Munk \& Von Seelen, 2012) and internationally (Dagkas \& Armour, 2012; Penney, 2002; Stidder \& Hayes, 2013). Our understanding of the processes promoting students' experiences of being in- 
cluded and/or excluded in PE remains limited. Two general focus points have prevailed in existing research on inclusion and exclusion processes in PE. First of all inclusion and exclusion have primarily been conceptualised as something being done to students (MacDonald, Pang, Knez, Nelson, \& McCuaig, 2012). Secondly, a categorical approach to the understanding of inclusion and exclusion processes in PE has been adopted (Penney, 2002). The starting point for the majority of studies has been particular social categories used for the division of students, mostly by gender (with a focus on girls as the problem group); but studies have also referred to skills as the main dividing characteristic (with a focus on the so-called "less skilled" students) or ethnicity (with a focus on ethnic minority students). The categorical approach may be criticised firstly for overlooking important variation within the specific category of students (Flintoff \& Scraton, 2006; Penney, 2002). The use of social categories gives the impression that individuals may be considered homogeneous groups based on common characteristics such as gender, ethnicity or skills (Penney \& Evans, 2002). Griffin (1985) has already highlighted this while pointing out that traditional generalisations concerning the behaviour of girls and boys posed the risk of camouflaging other (and more important) differences not necessarily related to gender. The use of social categories induces a grouping and not least a uniforming of individuals that seems counterproductive to obtaining a more nuanced understanding of inclusion and exclusion processes in PE (Penney, 2002). This has been expressed in the criticism of what Penney (2002) calls single-issue research, which is believed to provide a simplified representation of inclusion and exclusion processes in PE (Stidder \& Hayes, 2013). The relations between students' multiple identities (Penney, 2002) are reflected in interactions between students and in negotiations with teachers about the values and practices of PE classes. More knowledge about those interactions could thus contribute to a further understanding of the complexity of inclusion and exclusion processes in PE.

Our aim is to contribute to a social-relational perspective on inclusion and exclusion processes in PE. We define inclusion as those processes which promote students' participation in the learning processes of PE and exclusion as those processes that promote students' non-participation. The relational perspective leads us to pursue the question of how students' experiences of participation and non-participation in PE are influenced by the complex interactions within the group of students and within the values and practices of PE.

The article is structured in six parts including this introduction. The following section is a review of how existing research has contributed to our understanding of inclusion and exclusion processes in PE. In the third section, we will outline Lave and Wenger's (1991) social-relational learning theory as the basis for the sub- sequent identification of how students are being positioned or position themselves on the continuum of participation and non-participation in PE. In the fourth section, we will describe our methodological approach, while the fifth section will be concerned with analysis that shows how students' participation or nonparticipation is influenced by their experiences of meaningfulness and legitimacy that develop in relationship to other students and to the values and practices in PE. The sixth section will serve as a concluding discussion, where prospects for future research will also be examined.

\section{Previous Research}

As already mentioned, we believe that a categorical perspective on inclusion and exclusion processes during PE lessons has prevailed in existing research. In categorical research, individuals are often grouped based on the single aspect that seems most influential in accounting for the main differences between them. These studies have been important in pointing to differences between groups, although not sufficient for accounting for the complexity within them and for identifying possible issues across traditional groups of students.

The vast majority of these studies have focused on the exclusion of girls in PE (Flintoff \& Scraton, 2006). Several studies have shown that gendered practices and values have a negative effect on girls' participation in PE and that boys' control of the learning environment negatively affects girls' experiences and learning (Evans, 1989; Evans, Lopez, Duncan, \& Evans, 1985; Griffin, 1984; Scraton, 1993; Oliver, Hamzeh, \& McCaughtry, 2009). Furthermore, recent studies have found that girls often find it incompatible to identify themselves as girls and "doers" of PE at the same time and therefore try to avoid participation in PE (Cockburn \& Clark, 2002; With-Nielsen \& Pfister, 2011). A similar concern has been raised by O'Donovan (2003), reporting how some girls' ability to benefit from educational experiences in PE is hampered by anxiety related to being socially accepted by peers.

In addition to gender, recent research, especially in England, has focused on the experiences of ethnic minorities in $\mathrm{PE}$, and particular attention has been paid to the exclusion processes related to Muslim girls' participation (or rather non-participation) in PE (Dagkas \& Benn, 2006; Dagkas, Benn, \& Jawad, 2011; McGee \& Hardman, 2012). Although Islam does not in general prohibit girls from participating in physical activity (McGee \& Hardman, 2012), some Muslim girls do not participate in $P E$, since the practices and values of $P E$ are not perceived to be compatible with their cultural traditions and beliefs, e.g. in relation to girls being together with boys for activities like dancing and swimming (Dagkas et al., 2011), in relation to being physically active during Ramadan (McGee \& Hardman, 2012), and 
in relation to wearing the PE kit (Dagkas \& Benn, 2006).

Other studies have devoted some attention to students that by virtue of lacking physical skills are at risk of being excluded from PE. Quantitative studies suggest that these "less-skilled" students are excluded from both participation and learning (Corbin, 2002; van der Mars, 2006). This is supported by qualitative studies, which show that "less skilled" students are criticised and humiliated by their peers, especially during competitive ball games (Carlson, 1995; Grimminger, 2013; Portman, 1995a, 1995b). Furthermore, some of these studies show how students apply different strategies to avoid such situations. This could be pretending to participate, putting themselves in positions where they avoid interaction with others during ball games or skipping their turn when in a queue (Carlson, 1995; Griffin, 1984, 1985; Portman, 1995a).

While these studies have contributed valuable findings regarding how differences between groups of students are reflected in $\mathrm{PE}$, it is widely accepted today that the categorical perspective cannot fully capture inclusion and exclusion processes (Flintoff \& Scraton, 2006; Penney, 2002; Penney \& Evans, 2002; Stidder \& Hayes, 2013). Additionally, particularly within feminist research, an interest seems to have evolved in girls' multiple identities, rather than membership of a single social category (Azzarito \& Solomon, 2005; Flintoff \& Scraton, 2006). An example of this is discussed by Knez, MacDonald and Abbott (2012) who point out the diversity within the group of Muslim girls attending PE classes in England. They question the misleading assumption that the cultural and religious beliefs that restrict some Muslim girls' participation in PE are definitive and apply to all within this social category of ethnic minority students. Thereby, they also question the appropriateness of social categorisation. Another example is reported by Hills (2007), who shows how gender, ethnicity and ability interact in girls' experiences of inclusion and exclusion processes in PE classes in English secondary schools, and moreover how these experiences are influenced by the girls' social status and which fellowship group they belong to outside PE classes.

In this article, we will pursue a social-relational perspective on processes of inclusion and exclusion by using the conceptual tools of situated learning originally developed by Lave and Wenger (1991). Others have used this theoretical perspective to describe relations between students in PE and relations between PE and other forms of physical culture (Kirk \& MacDonald, 1998; Kirk, 1999; Williams \& Bedward, 2002). A recurring argument amongst these authors is that students are alienated from PE in its present form because learning in PE has not kept pace with developments in other areas of the physical culture in which students are involved outside the framework of the school. However, Wenger's theoretical perspective, and particularly the significance of students' feelings of alienation or not, have not yet been thoroughly empirically investigated. In particular, inclusion and exclusion processes in PE have not been empirically investigated in a Nordic context. The Nordic context represents a special case in the sense that a large proportion of students participate in sport in their leisure time (in Denmark, 81\% of 13-15year-old adolescents) (Laub \& Pilgaard, 2013). Still, it is worth inquiring into (in this case Danish) students' experiences of inclusion and exclusion processes in $\mathrm{PE}$, since school sport and leisure sport are organisationally and educationally separated, being structured by voluntary coaches and professional teachers, respectively.

\section{Theory}

In this study the relational understanding of inclusion and exclusion processes is based on the theoretical framework and concepts developed by Lave and Wenger (1991). Lave and Wenger introduced the idea of situated learning; their work also outlined the concept of legitimate peripheral participation in communities of practice, which was further developed by Wenger in 1998. Originally the concept was developed on the basis of five case studies on learning in apprenticeships. However, Lave and Wenger (1991), as well as others (Kirk \& MacDonald, 1998), have suggested that the theory could also be beneficial in analysis of schooling, as well as other specific educational forms. This is consistent with our aim to examine how the theory could be applied to learning in PE classes.

In line with Kirk and MacDonald (1998), we understand a community of practice as "any collectivity or group who together contribute to shared or public practices in particular spheres of life" (Kirk \& MacDonald, 1998, p. 380). The group of students and teachers in a PE class would be an example of a community of practice. These students and teachers are at the same time part of other communities of practice such as the school, sports clubs etc. To describe the class as a community of practice allows us to identify the social relationships, practices and values that shape students' participation or non-participation within this community and to explore the community's relationships to other overlapping communities of practice such as the broader context of school, leisure exercise and sports in which students also participate.

Legitimate peripheral participation describes engagement in a social practice that entails learning (Lave \& Wenger, 1991). As stressed by Lave and Wenger (1991), the term legitimate peripheral participation does not imply that there is a centre or core of a community of practice. On the contrary peripherality is a way to acknowledge that there are "multiple, varied, more or less engaged and inclusive ways of being located in the field of participation defined by a community" (Lave \& Wenger, 1991, p. 36). With this perspective different levels of participation in PE do not only 
derive from members facing structural limitations but also from students having different interests in $P E$, making diverse contributions to the activities of PE and holding varying viewpoints about PE. This is consistent with our aim of contributing to the development of a social-relational perspective on processes of inclusion and exclusion in PE, as experienced by students and taking the values and practices in PE into account.

According to Lave and Wenger (1991), legitimate peripheral participation is a crucial condition for learning. Thus, Wenger (1998) defines four categories of participation; the insiders and the peripherals, both of which are characterised by legitimate peripheral participation; and the marginalised and outsiders, both of which are not characterised by legitimate peripheral participation. We can presume that these four categories could also be identified in the community of practice of a PE class, so the criteria for identifying the four types of participation in our empirical data could be deduced from Wenger's description of the patterns of participation and non-participation typical for insiders, peripherals, the marginalised and outsiders. Thus, Insiders are the students who fully identify with the practices in PE; they are students who have a strong commitment to PE, who make an effort to achieve a good result and who have the greatest responsibilities. The peripherals also contribute to practices in $\mathrm{PE}$, although they do not perform at the same level as the insiders, nor do they have the same level of responsibilities. Still, the peripherals' experiences of participation are stronger than their experiences of non-participation. In contrast, the marginalised are identified by their nonparticipation rather than their participation; their contributions are very limited and it is hard for them to identify with practices in PE. Outsiders are characterised by full non-participation; they do not show up for PE classes or place themselves outside of the activities of the class e.g. on benches or mats along the walls or in rooms nearby the gym.

Of importance for the processes of inclusion and exclusion, Wenger (1998) states that two conditions are critical for members of a community of practice to be considered as legitimate peripheral participants and therefore included in the learning processes within that community. The first is that members are ascribed legitimacy by other members and the second is that members experience the activities within the community as meaningful. The focus in our analysis of students' participation and non-participation in PE is firstly an identification of ways in which students gain legitimacy and are deprived of legitimacy in PE and secondly which conditions matter for students to experience PE as meaningful.

\section{Method and Material}

A case study was conducted to examine the complex relationships involved in students' participation or nonparticipation in PE. The single case study was chosen because of its potential to cover a complex phenomenon through various methods, along with the options for bringing forward unknown relationships and variables leading to a rethinking of the phenomenon being studied (Stake, 1981).

The case school was selected through purposive sampling "based on the assumption that one wants to discover, understand, gain insight; therefore one needs to select a sample from which one can learn the most" (Merriam, 1998, p. 48). The students in the school should represent a variety in gender, ethnicity and physical skills level as we know from earlier research that these are some of the variables that could affect the processes of inclusion and exclusion in PE. Furthermore, the school was selected on the basis of accessibility and geographic proximity. The case school is situated in a medium-sized city in Denmark. A majority of children are from the lower classes and a relatively high percentage of students have ethnic minority background (approximately 40\%).

To enrich and validate the findings, multiple types of material were gathered through different research methods. This study is based on observations of PE classes in the $6-8^{\text {th }}$ grades (pupils aged 11-14) over a period of six months, as well as 6 focus group interviews with selected students from these classes and 5 individual interviews with the PE teachers responsible for the observed classes. The use of observations along with teacher and student interviews also served to triangulate data.

To be more specific, a total of $42 \mathrm{PE}$ lessons, each lasting 90 minutes, were observed over a period of six months. In the $6^{\text {th }}$ grade, 18 lessons were observed, in the $7^{\text {th }}$ grade it was 13 lessons, while 11 lessons were spent with the $8^{\text {th }}$ grade. The smaller number of observations in the $7^{\text {th }}$ and $8^{\text {th }}$ grades were a consequence of the school's cancellation of lessons caused by holidays, school arrangements etc. All observations were made by the first author as a non-participant. The focus of the observations was the variety in students' participation and non-participation, and special attention was given to relations between students, between students and teachers and between students and the content of PE. Short notes were taken during the lessons and the observations were further described as soon as possible after the end of the observed lesson. Throughout the six-month period, several "informal conversational interviews" (Patton, 1990) with teachers and students also took place before, during and after the PE classes. At first, the observer initiated the conversations with students, but gradually students approached the first author at their own initiative. The conversations were recorded as notes at the end of each informal conversation (Patton, 1990).

Approximately three months into the period of ob- 
servations, the relevant teachers $(2$ females and 3 males) were interviewed individually. The aim of these interviews was to unfold the teachers' interpretations of the processes of inclusion and exclusion and to collect knowledge about the ways teachers structure the values and practices of PE. At the end of the interview, teachers were asked to indicate their students' levels of participation in a diagram, so that the most participatory students were placed closest to the inner circle and the least participatory students were placed furthest to the inner circle (see Figure 1). This was followed by questions inquiring into the teachers' understandings of participation and non-participation in PE and the positions taken up by different students. The intention was not to have all students placed in the diagram, but to gain knowledge about typical positions of participation and how these positions were categorised and talked about by teachers.

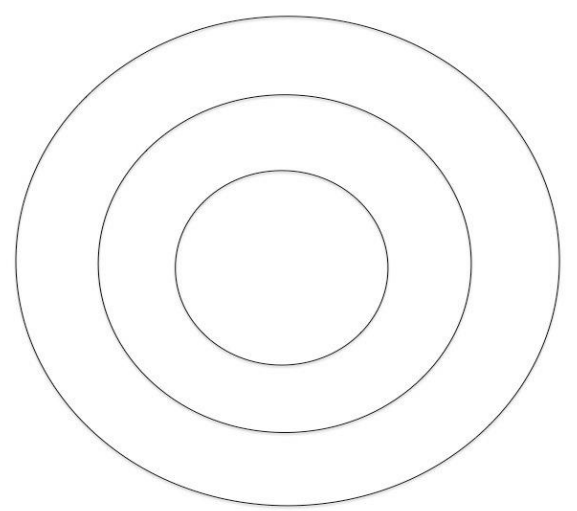

Figure 1. Diagram of students' levels of participation in $P E$. The circles indicate different levels of participation with the inner circle representing the most participatory students and the outer circle representing the least participatory students. Students not participating at all were placed outside the diagram.

In the last month of the observation, students were selected for focus group interviews. By this time, the observer had become familiar with the students and the students had gained trust in the observer; they initiated conversations, asked questions and seemed happy to share their experiences in PE. Two focus group interviews (each with 6-9 students) were conducted in each of the three PE classes and a total of 46 students were interviewed. On the basis of observations, students from each of the four categories of participation defined by Wenger (1998) were invited. It was intended that students that seemed to contribute considerably and be highly valued in PE, as well as students that seemed to contribute less and be less valued in PE were represented in each interview. Furthermore, students were selected to represent specific characteris- tics of each class observed in terms of ethnic origin, skill level and gender. As the composition of the focus group is important to facilitate an active and freeflowing discussion during the interview (Morgan, 1996), PE teachers reviewed the composition of each focus group to ensure that it would not interfere with the students' will to talk freely. The composition of the focus groups tried to balance both the importance of homogeneity (Morgan, 1996) and heterogeneity (Krueger, 1994).

Students were informed about the aim of the interviews and procedures for confidentiality. Three of the 50 students invited did not want to participate in the interview, and one student did not attend school on the day of the interview. The aim of the focus group interviews was to inquire into students' experiences of their own and other students' participation and nonparticipation in PE. Thus, students were asked questions about what could encourage or discourage their participation (and non-participation). Furthermore, at the end of the interviews, each student was given a diagram (see Figure 1), and asked to position him or herself in the diagram, to indicate their level of participation. After having placed themselves, students were given a shared diagram and asked in confidence to position at least three of their classmates in each of the diagram's circles as to gain further knowledge about typical positions of participation and non-participation and how these positions were categorised and talked about by students.

All interviews were conducted in a quiet room away from the gym to ensure participants felt comfortable. The interviews lasted between 60 and 90 minutes. All interviews were conducted by the first author, taperecorded and transcribed verbatim. In the analysis to follow, all students and teachers mentioned are anonymised and information about individual students and teachers is limited. Data were analysed throughout the research process using the principles of systematic combining (Dubois \& Gadde, 2002), which has been described as an iterative process between the case, the empirical world, the framework and the theory or model being developed (Dubois \& Gadde, 2002).

\section{Results and Analysis}

In the process of analysing the forms of participation and non-participation identified through observations, interviews and diagrams we developed Figure 2. The model served as the starting point for further analysis of the dynamic interactions between students and the values and practices of PE that were influencing students' participation and non-participation in PE. 


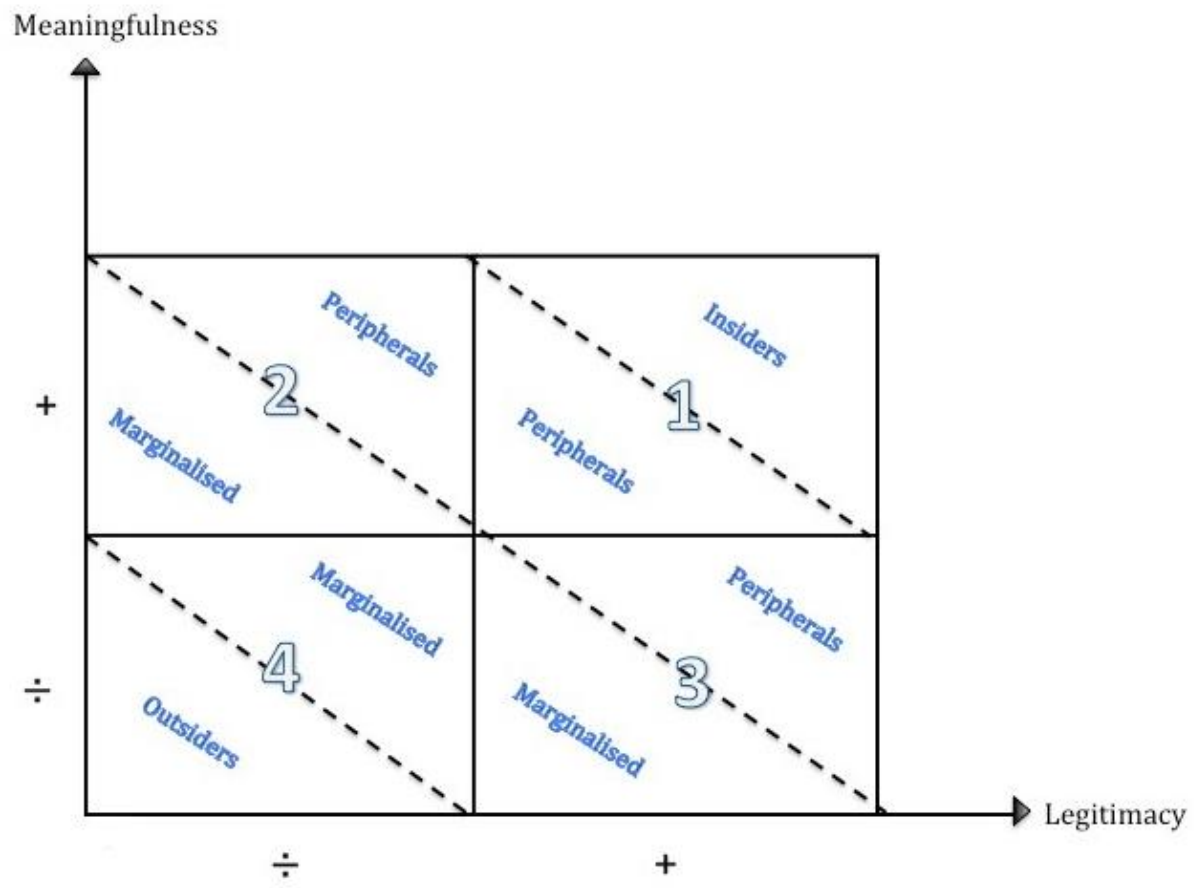

Figure 2. Students' positions of participation in PE.

In Figure 2, Wenger's (1998) four positions of participation are located in relation to the degree of perceived legitimacy and meaningfulness. In the first field of the figure, students' participation is characterised by both legitimacy and meaningfulness. Here the degree of perceived legitimacy and meaningfulness becomes the determining factor in students' positioning as an insider or peripheral. In the second and third fields of the figure only one of the two conditions of inclusion is sufficiently met. What becomes crucial for students' positioning as either peripheral or marginalised participants in the second field of the figure is the degree to which legitimacy is lacking and in the third field of the figure the degree to which meaningfulness is lacking. In the fourth field of the figure, neither of the two conditions is sufficiently met; what becomes crucial for students' positioning as either a marginal participant or an outsider is the degree to which both legitimacy and meaningfulness is lacking.

In order to show the variations in students' participation and non-participation in PE, the following analysis is structured on the basis of the four categories of participation in Figure 2. However, in practice the borders between categories are of course more fluid. The empirical examples represent practices and interactions repeatedly observed in the PE classes. Furthermore, the examples are chosen to reflect the values expressed by students and teachers in relation to students' participation and non-participation in PE.

\subsection{Field 1: Participation with Meaningfulness and Legitimacy}

In many of our observations, the processes of inclusion and exclusion in PE classes unfolded in the relationships between students who, in the specific activity of $\mathrm{PE}$, could be described as novices (or newcomers by Wenger (1998)) and masters. In these observations it became clear that the participant position of the novices largely depended on the legitimacy they could be ascribed by the masters. While the relationship between the skilled students (here the masters) and the less skilled students (here the novices) has often been described as exclusionary, this relationship could also encourage learning and provide a chance of making $P E$ meaningful to the novice students in PE.

Today the students have been allowed to choose whether to play football or dodgeball. Eight boys and three girls, including Mary, Alice and Michelle, choose to play football. While all the boys play football in their leisure time, Mary, Alice and Michelle do not have any qualifications to the game. The teacher decides that a "girl-score" counts double. To take advantage of this rule, Steven asks Mary and Alice to go to the opponent's goal and place themselves by each of their posts. For long periods of time, the game takes place around the opposite goal; however, Mary and Alice stay at the posts as they have been told. Alice says that it's better to let the boys do the job themselves. Mary and Alice rarely receive the ball and when they do, it is by coincidence. The boys do not seem to see the girls. Sometimes the boys intercept the ball on its way to the girls and sometimes they take over the girls' positions in the field. The same pattern applies to Michelle, who plays as a defend- 
er/goalkeeper on the other team. Sometimes the ball randomly comes into Mary, Alice or Michelle's possession and Alice actually manages to score a goal once. It results in loud praise from the boys. Generally the boys praise Mary, Alice and Michelle the few times they touch the ball. The atmosphere is intense, but nobody is yelling at each other if someone loses the ball or misses an obvious opportunity to score. If this happens the students quickly calm each other down. At some point Alice and Michelle indicate that they are thirsty. Typically, Mary and Alice would go and have a sip of water together. However, in this situation Alice asks Michelle to stay until she comes back, so the team does not need to do without both of them, while they are gone. (Notes from observation, 30 April 2014)

Mary and Michelle both participated in the subsequent focus group interviews. When asked about a good lesson in $\mathrm{PE}$, a lesson that was meaningful to them and in which they learned something, they independently of each other described the lesson in which they played soccer with the boys.

Because of the boys' technical and tactical skills and experience in football, they participated as the masters on the team. They direct and distribute the play, they take most responsibility and they contribute considerably to the way the game is developing (upper corner field 1, Figure 2). On the contrary, the girls' lack of experience with and competence in football place them in the position of newcomers. According to Lave \& Wenger (1991, p. 110) the tasks of newcomers "tend to be positioned at the ends of branches of work processes rather than in the middle of linked work segments". In that sense, the participation of Mary, Alice and Michelle is enabled rather than restricted by their tasks being short and simple, the costs of their errors being small and their responsibility for the activity as a whole being little. As newcomers Mary, Alice and Michelle are highly dependent on the boys recognising them as legitimate members of the community of practice. The teams only consist of 5-6 players and so the girls' contribution to the game becomes significant although limited. The teacher's decision to double up a girl score further contributes to the legitimacy that the experts of the team acknowledge for Michelle, Mary and Alice because it raises the value of their contribution. Although the contribution of Mary, Michelle and Alice is limited, they themselves also seem to have a feeling that the role they have on the team is meaningful and valuable to the other players. This is, for example, reflected when Mary and Alice choose not to leave the game at the same time when they get thirsty and in the way all three of the girls talk seriously about the tasks they are given in the match. That Michelle, Alice and Mary are able to participate in a legitimately peripheral way (lower corner field 1, Figure 2) entails that they despite being newcomers have access to the mature practice of the experts (Wenger, 1998). So the newcomers' authentic experience of being participants in a "real" football match together with masters, could in part explain the positive experience of learning expressed by Michelle and Mary in relation to the specific lesson described.

Despite Mary and Michelle's expressed experience of learning, the situation described seems problematic for several reasons when examined from a gender perspective. First of all, the teacher's rule "girls' scores count double" stigmatizes the group of girls as noncompetent. The teacher states the rule before the game has even started and so takes for granted that all girls are less competent than boys at playing football. This way of structuring the values and practices in $\mathrm{PE}$, also found in other studies (see e.g., Scraton, 1992; Flintoff \& Scraton, 2006; Hay \& MacDonald, 2010), could contribute to a stereotyping of girls' competence in PE lessons. Furthermore, the teacher does not intervene in the situations in which boys clearly take over the responsibility the girls have been given. As described by Wenger (1998), mutual engagement can be a vehicle for both sharing ownership of meaning and for denying negotiability. If negotiability is denied, like in the case of not recognising the contributions of some members of the community of practice in $P E$, members develop "an identity of non-participation that progressively marginalises them" (Wenger, 1998, p. 203). Over time Michelle, Alice and Mary therefore risk losing their sense of legitimacy, thereby shifting from the position of peripherals (lower corner field 1 , Figure 2) to a position of marginalisation (lower corner field 2, Figure 2). However, this risk is not only related to the relationship between genders but between novices and masters in general. For Mary, Alice and Michelle to experience a continued sense of meaning and legitimacy, they must have an opportunity to not only experience "the masters' game" but to develop their own communicative, technical and tactical competence as football players and, in this way, obtain greater legitimacy. For this to happen, it seems necessary for the teacher to play a more active role than was the case in this observation and others.

Finally, we have to be aware that although Mary and Michelle expressed an experience of participation in the case described, this could also be a result of Mary's and Michelle's desire to be viewed positively by the interviewer and the other students participating in the interview. Grimminger (2014a) has described how less sporty children use different defence strategies and deny non-recognition experiences in order to explain their own role and to maintain personal control. In the next section, we will examine in-depth how and why students are deprived of legitimacy in PE and how this affects students' participation and nonparticipation. 


\subsection{Field 2: Participation without Legitimacy}

Although the relation between the novices and the masters, as shown in our first example, could be a vehicle for learning, this relation could also be the reason for some students' experiences of non-participation. Lave \& Wenger (1991) ascribe this duality to the relation of power involved in legitimate peripherality.

As a place in which one moves toward more intensive participation, peripherality is an empowering position. As a place in which one is kept from participating more fully it is a disempowering position. (Lave \& Wenger, 1991, p. 36)

The empowering position of peripherality is clearly expressed by Andrew, a peripheral student, as scepticism towards the interviewer's question about the option of separating the less skilled from the more skilled students in PE.

Try to imagine that all the less skilled were in here, then how could we learn? You can learn from the skilled, how they do things. (Andrew, authors' translation)

In that sense Andrew acknowledges the potential of learning from more adepts practitioners like the masters. However, in other cases the students were very aware of the disempowering position of being kept away from participation. These cases were mainly related to experiences of not being ascribed sufficient legitimacy and are, for example, reflected in the way John describes his experience of being in a marginal position in PE (lower corner field 2, Figure 2).

Usually it is only just the skilled students who play together all the time. And then all the others, that is the ones who are not that skilled, they never get the ball. They never ever get the ball. Well, maybe they get it once, but then they should throw it back to the same people for them to shoot, and it just continues like this. (John, authors' translation)

Situations of more skilled students being restrictive for the less skilled students' participation in PE as described by John, were very easily recognised in our observations. So, only seldom were the skilled students aware of ascribing legitimacy to the less skilled students, for example by passing the ball to the less skilled students. Furthermore, in situations where this occurred the less skilled students often rejected the possibility to participate in the game.

The students are playing Danish Dodgeball. Tom, a less skilled student, and Paul, a highly skilled student, stand next to each other. Tom catches the ball. He turns immediately towards Paul and asks him if he wants to shoot the ball. Tom shrugs and says, no, I don't care. Not until then does Paul shoot the ball. (Notes from observation, 23 April 2014)

Paul's behaviour was the exception rather than the rule among the skilled students. This is consistent with Hills' (2007) study, reporting that even though some students, like Paul, made a conscious attempt to include the less skilled students in PE, exclusion seemed to have been the normative practice among the skilled students. In our interviews, the skilled students did reflect on not passing the ball to the peripherals being an unacceptable form of exclusion. However, many of them did not blame the skilled students but rather the less skilled students for this exclusionary relationship.

We give them the ball, but they give it back to us straight away. If I have the ball, they say, "no, you throw, I can't make it, you throw. (Louise, authors' translation)

The behaviour of the less-skilled students described above could possibly be explained by earlier experiences of not being ascribed legitimacy or more broadly speaking not being recognised in PE. Grimminger (2014a) has shown that non-recognition experiences, among which could be experiences of non-legitimacy, are negatively associated with both physical selfconception and self-esteem, however, only among sporty children. In our interviews some students, especially the more skilled ones, acknowledged that the behaviour of the less skilled students could be based on a lack of self-esteem developed in PE over the years; they did not, however, seem to acknowledge their own part in this. Rather both the skilled students and the less skilled students explained their non-participation as not trying hard enough. This way of denying their lack of legitimacy in PE has been described by Grimminger (2014) as a strategy of "self-handicapping" and self-protection.

The significance of physical skills for the recognition and participation of students in PE have also been described by others (Carlson, 1995; Griffin, 1984, 1985; Grimminger, 2013; Grimminger 2014b, Hills, 2007; Portman, 1995a, 1995b). Even if physical skills are undoubtedly important for the legitimacy ascribed to students, in our observations and interviews with students it also became clear that students' physical skills were neither a guarantee nor a prerequisite for the legitimacy ascribed. Legitimacy, as in the following observation, also seemed to be ascribed and deprived through students' social relationships.

The students play Danish dodgeball. Susan, Michael and Kelly are all on the same team. Kelly and the other girls on the team often play the ball to Susan, 
who often ends up shooting the ball. In the position beside Susan stands Michael. He tries hard to get hold of the ball and to make the others pass to him. He waves his hand and shouts "Pass to me! I am really good!" While still not having received the ball, Michael runs in front of Susan to snatch the ball. When Kelly receives the ball, she really has to make an effort to pass Susan the ball over the head of Michael. Kelly manages to pass the ball to Susan, but the pass has taken too much time and all the opponents have moved away. Susan turns angrily towards Michael and asks him not to block the pass. (Notes from observation, 23 April 2014)

It is pivotal for the understanding of this observation that Michael's skills in Danish dodgeball are not different from Susan's. What presumably separates Michael from Susan in this observation are the communities of practices of the two outside of PE. Susan is a friend of Kelly and the other girls on the team-Michael is not. Generally, Michael is not popular among the girls in the class; in PE they often turn their back on him or look at him without sympathy. So the relations between the girls and between Michael and the girls hamper Michael's participation, placing him in a peripheral position (upper corner field 2, Figure 2) and at risk of being marginalised (lower corner field 2, Figure 2) in this specific case. The significance of social relations or popularity among peers has also been reported in studies by Hills (2007), Grimminger (2013) and O'Donovan (2003). Hills (2007) found that girls' physical skills, as well as girls' social relationships, were important in shaping their involvement in PE and for the power relations between the included and the excluded students. The relevance of social relations was also confirmed in our interviews when students talked about team selection a strategy described as a typical way of being ascribed legitimacy or not in PE (Grimminger, 2014b). When asked who they would typically choose when they were forming the teams on their own, students explained that some students chose "the highly skilled" and others chose "their good friends". While the strategy of choosing best friends was typically described as something done by girls, the strategy of choosing the highly skilled was typically described as something done by boys. In addition to the different preferences of boys and girls also highlighted in Grimminger (2014b), the students we interviewed also described how preferences of team selection differed between skilled and less skilled students.

The skilled ones, they just want to have the best team and the ones, who don't really bother about the game, they just want to be together with someone they like. (Louise, authors' translation)

So which students are being ascribed legitimacy and from whom students prefer to be ascribed this legitimacy, seem to be related to the physical skills of students as well as their social relations.

When comparing the experiences of Michelle, Alice and Mary in our first example with the experience of Michael in our second example, it is interesting to note that students' experiences of being ascribed legitimacy are not directly proportional to the number of times they touch the ball. Participation by Michelle, Alice and Mary as well as Michael was characterised by only touching the ball a few times during the game. While Michelle, Alice and Mary experienced sufficient legitimacy, this was not the case for Michael. So students' experiences of legitimacy are not only a result of how much legitimacy they are ascribed, but also of how much legitimacy they expect to be ascribed. Sufficient legitimacy is thus not absolute but relative; it is based on a subjective experience and therefore cannot be judged solely on the basis of observation but also requires analysis of the meaning students attach to PE.

\subsection{Field 3: Participation without Meaningfulness}

In the classes we observed, there was generally a strong focus on the social activity and less focus on development of students' physical capabilities and on promoting theoretical insight and reflection. As illustrated in the next empirical example, this lack of focus on the improvement of students' skills and knowledge became highly significant for why some students did not experience the meaningfulness of PE and therefore adopted a marginal position (lower corner field 3, Figure 2).

Since the students from $7^{\text {th }}$ grade were planning to go on a trip and part of the program would involve physical activities, the teachers had planned that all students should go for a $3 \mathrm{~km}$ run in every PE lesson in the period between students' autumn holiday and their summer break. The teachers had pointed out a route of $1 \mathrm{~km}$ and students were asked to run three laps. The teachers had a protocol whereby it was noted every time a student completed a lap. Since the teachers knew that some of their students would have difficulties running due to being overweight, obese and/or having poor physical fitness, they allowed students to choose their own pace and to run with whomever they wanted.

In the observation period in this study, many students took up a marginal position (lower corner field 3, Figure 2). They made no attempt at running, but were strolling along in smaller or bigger groups. A few students sped up when they passed the teachers; others were just looking up while continuing to chat. During the interviews, several students described how they deliberately skipped PE in that unit or intentionally forgot their sportswear or made up injuries to avoid par- 
ticipation. Elisabeth is one of the students that sometimes ran the whole $3 \mathrm{~km}$ and sometimes choose to stroll along with some of her classmates. She tells me that she does not feel like running but that it is important for her to have a good relationship with the teachers. However, that kind of meaningfulness does not seem to be sufficient to maintain Elisabeth in a peripheral (upper corner field 3, Figure 2) rather than marginalised position (lower corner field 3, Figure 2). Elisabeth clearly expresses that she does not believe the teachers when they tell them that the running program can make students improve their physical fitness.

That is not why. It is just something (the teacher) says. If you only run once a week, it does not make a difference. You also have to run in your leisure time. (Elisabeth, authors' translation)

So the purpose of these PE activities appears meaningless to Elisabeth. Other students also do not seem to find the purpose of the running sessions relevant either because they already do a lot of physical activity in their leisure time or because they never do any physical activity. Finally, for several students it is the practice of running the three laps rather than the goal of running the three laps that makes PE meaningless. Andrew and Monica are two of the students that find it pointless to run the same lap all over again and in their opinion they only do it to satisfy the teachers. What this signifies is that they are offered only very limited opportunities to develop as runners and thus to move from a marginal to more peripheral or full participation. The prerequisites of moving towards full participation have been described by Kirk \& Kinchin (2003):

As a legitimate peripheral participant in any community of practice...a learner's trajectory towards full participation can only be realized through the increasing mastery of the goods-the knowledge, skills and dispositions internal to that practice, whether this be tailoring or midwifery or baseball playing. (Kirk \& Kinchin, 2003, p. 230)

In the running classes students were not offered many opportunities to develop the knowledge, skills and dispositions relevant to running. In fact they were not offered the prospect of any other profits than the possibility of physical activity and improved health. This adds to the concern expressed by Kirk (1994, p. 49) that PE is "being lost in the public health rhetoric". In our interviews, more students questioned the practice of separating running from other sports. They did not mind running but argued that they liked running better when it was a part of doing sports.

The lack of focus on the development of students' knowledge, skills and dispositions were not reserved for the running classes but was also very symptomatic for the way ball games were taught. Generally, the focus of the classes was more on what students should do than on what students should learn. This was also expressed by several of the interviewed teachers; for example one said that "for many years PE has been too much fun and too little learning". In the competitive team game units we observed, very limited time and assistance were offered to students for the development of their skills and knowledge. Rather, most of the time teachers simply let students play the games. In the interviews only one teacher seemed to hold strong goals for the development of students' physical competence, including their technical skills and tactical awareness. On the contrary, many of the teachers expressed a contradiction between giving the students a good experience and paying attention to the improvement of their physical skills or their development of theoretical knowledge. However, while unintentional on the part of the teachers, this practice seemed to deny students the possibility of moving towards full participation in $\mathrm{PE}$ and to promote exclusion rather than inclusion. Furthermore, the limited perspective of learning in PE experienced by students made it difficult for many of them to relate PE to learning as the central meaning of school and to their future possibilities of gaining from PE. In our interviews many students questioned the relevance of their participation in $P E$ for their future lives and careers. When contrasting mathematics with PE students said:

$P E$ is ok, but you see, we cannot really use it for anything. I haven't learned anything in PE. Mathematics you should use the rest of your life (Laila, authors' translation)

You can use it [Mathematics]...(Elsa, authors' translation)

In your future...(Marc, authors' translation)

To get a job. To get an education (Laila, authors' translation)

The importance of students believing in the usefulness of learning, has clearly been captured by Alexander (2001) , who states that:

It is not enough to say to someone, learn and you will increase your life chances. The learner needs to know that they have the power to apply their learning and to benefit from it. (Alexander, 2001, p. 30)

That students lacking experiences of meaningfulness in PE could be related to the evidently limited transfer of learning experienced by students in some PE-classes has also been noted by others (Kirk \& MacDonald, 1998; Penney \& Chandler, 2000; Kirk \& Kinchin, 2003). 


\subsection{Field 4: Participation without Meaningfulness and Legitimacy}

Characteristic of several of the students we observed was that during the lesson they moved from being in a peripheral position to becoming marginalised (upper corner field 4, Figure 2) or even outsiders (lower corner field 4, Figure 2). Based on their past experiences, other students chose from the beginning of PE classes to be outsiders and did not take part in the joint enterprise of the community of practice (lower corner field 4 , Figure 2). The reason for this seemed to be a combination of two circumstances; that students did not experience $P E$ as meaningful and that they were not ascribed the sufficient legitimacy. In contrast to what has been indicated in earlier studies primarily focusing on students who are excluded, the students who chose not to participate in one or more of the observed lessons in PE were not only low skilled students but also higher skilled students, boys as well as girls and ethnic Danish students as well as students of other ethnicities. While a lack of legitimacy, as earlier argued, was mostly related to the physical skills and social relations of students in this study, the experience of PE as meaningless also seemed to be significant across gender, ethnicity and skills level. This points to the importance of also searching for other reasons for students' participation and non-participation in PE.

Furthermore, through our observations and interviews it became clear to us that the meaningfulness and legitimacy that students believe they could achieve by participating in PE should be seen in relation to the meaningfulness and legitimacy students believe they could achieve by not participating. Some students are tempted by the possible legitimacy they can gain if they choose to be outsiders together. In some of our observations, the outsiders even developed a kind of social community around their non-participation. Access to that community was conditioned on members' non-participation in PE.

Sometimes you can feel different because the other students participate in PE and you do not. But on the other hand there are also others who do not participate, and so you are just like them. (Evelyn, authors' translation)

The legitimacy and experience of meaningfulness that students like Evelyn could gain by participating in PE, was not always sufficient to offset the legitimacy and meaningfulness they could gain by being outsiders. Evelyn was not being excluded from PE but she chose to exclude herself from it in order to be included in another community of practice. Wenger points to the ways in which one community of practice is developed not only in relation, but even in opposition to another: "each side is defined by opposition to the other and membership in one community of practice implies marginalisation in another" (Wenger, 1998, p. 168). More specifically, O'Donovan (2003) has pointed to the deleterious effects of a PE culture valuing nonparticipation rather than participation in $\mathrm{PE}$.

The deliberate choice made by students not to participate in PE seemed to be further reinforced by the dominant culture of the observed classes. Students often talked about participating in PE as a choice rather than a necessity. For example, they explained their choice not to participate or not to attend as "having other things I would rather like to do", "feeling tired" or "being busy with after-school jobs". Furthermore, students did not describe any consequences of not participating or failing to attend. The students' experiences of non-participation or non-attendance being without consequence were largely confirmed by our observations. Lessons seldom built upon previous lessons in any direct manner and teachers did not always notice that some students were missing. Furthermore, students were very aware of how easy it was to be exempted by faking an injury, presenting a counterfeit notice from their parents or pretending to have forgotten their PE clothes on days they did not "feel like" participating. The fact that at the time of our data collection there was not any formal evaluation of students in PE in Denmark only seemed to contribute further to students' experience of non-participation and nonattendance being inconsequential and to their experience of participation as meaningless. Many students more or less explicitly conceptualised PE as a break from learning rather than a place for learning. The low status of PE among students, however, does not seem to be limited to Denmark (Flintoff \& Sracton, 2001).

In addition to the kind of students mentioned above, we also noted another kind of outsiders or marginalised students (Field 4, Figure 2), those for whom non-participation became an active and conscious act of showing who they were not. Wenger (1998) has argued that

We know who we are by what is familiar and by what we can negotiate and make use of, and we know who we are not by what is unfamiliar, unwieldy and out of our purview. This is an important point. We not only produce our identities through the practices we engage in, but we also define ourselves through practices we do not engage in. Our identities are constituted not only by what we are but also by what we are not. (Wenger, 1998, p. 164)

While one student had a very visible way of showing his non-identification with PE, for most others, mainly less skilled students, non-identification was simply expressed by being indifferent to PE. In the observations, the former did not seem to take any notice of neither being ascribed legitimacy or not. Also, when talking to 
students, what happened in PE did not seem to matter to them. Even if this could be an act of selfhandicapping, based on our observations and informal talks with students, it seems more likely that both participation and non-participation in PE only contributed very little to the self-identification of these students. Wenger (1998) has described this in relation to other communities of practice.

Realizing that you are not a claims processor may contribute in a small way to your sense of self but, unless you are trying to become one, that realization remains inconsequential. (Wenger, 1998, p. 165)

So in the case of these students, not being a sports person only contributed in a small way to their sense of self. This has also been evidenced by Grimminger (2014a), who reported that PE had no self-relevance among less sporty children.

In contrast to the students showing their nonidentification with being a physically active person through indifference to $P E$, another boy had a more visible way of showing his non-identification. In our observation he could be very destructive of the teaching, both by answering back to teachers and through acting in defiance of what was asked of him. He wanted to send a message of "try me and I will show you that you can never make me become a sporty person" to us, as well as to the teachers and other students. In the interviews and our informal conversations with him, he made a big point of both showing what he was not (a person who liked PE) and what he was (a person who liked playing computer games). He told us that he only wanted to participate in PE if he could have "a computer with a lot of games, a refrigerator with candy and coke and a comfortable beanbag". He contrasted the values and practices of the community of practice of $\mathrm{PE}$ with the values and practices of the community of practice of computer gamers, which he wanted to be part of. That the incompatibility of identities can restrict participation in PE is confirmed by studies showing that some girls feel caught between the values of feminism and the values of masculinity in PE (Cockburn \& Clark, 2002; With-Nielsen \& Pfister, 2011; O’Donovan, 2003).

\section{Concluding Discussion}

This case study aimed to contribute to a social relational-perspective on inclusion and exclusion processes in PE. In order to understand the complexity of students' participation and non-participation, a case was selected in which there was a highly differentiated composition of students and a variety in gender, skills and ethnicity that, according to earlier studies, was critical for students' participation and non-participation in PE. On the basis of Etienne Wenger's conceptual tools, we showed that a student's degree of participa- tion in PE-classes is closely related to the legitimacy ascribed to them and the meaningfulness of $P E$, as experienced by the student. While some students were excluded from PE as they did not have the physical skills and social relations necessary to be ascribed legitimacy, others chose not to participate because PE was not meaningful to them.

The present study focused on how students' experiences of participation and non-participation in PE are influenced by the complex interaction between the students themselves and the values and practices of $P E$. The findings of the study provide a number of insights into how students are excluded from participating in learning processes in PE and why some students choose not to participate; the latter finding has not gained much attention in earlier research in this field.

In the case of students being excluded from participation, we found that interactions between students were important for how they were ascribed or deprived of legitimacy in PE. Other studies have pointed to team selection proceedings as an opportunity for students to transmit recognition and non-recognition (Hills, 2007; Grimminger, 2014b). As teachers often formed the teams in the classes we observed, there was seldom an opportunity for students to do this in the study. However, we found that legitimacy was often ascribed to and deprived from students during games when teams had already been formed. We found that being passed to or passed over, as well as being or not being assigned a privileged position were typical ways of being ascribing or depriving someone of legitimacy. Hills (2007) has pointed to such practices as important for processes of inclusion and exclusion in $\mathrm{PE}$. In contrast to studies focusing on the exclusion of low skilled students, we found that even if students' physical skills were important, they were neither a guarantee nor a prerequisite for the legitimacy the students were ascribed. In accordance with recent studies on processes of inclusion and exclusion in PE (Grimminger, 2013; Hills, 2007; Grimminger, 2014b), we found that in addition to students' physical skills, legitimacy was also ascribed and deprived on the basis of students' social relations. So a highly skilled student with the "wrong" social relations could risk being excluded from participation, while a less skilled student with the "right" social relations could avoid being excluded from participation.

In addition to students being excluded, we also became aware of several students choosing not to participate. In addition to the possibility of the choice being a defensive strategy (Grimminger, 2014a), we can also point to other possible reasons. First of all, students chose not to participate in PE in situations where the learning practices and/or values of $\mathrm{PE}$ are not meaningful to them. In such cases, non-participation could be either a reaction to not wanting to be identified with sport and physical activity; not having access to the de- 
velopment of the knowledge, skills and understanding necessary for moving towards full participation; or the experience of learning in PE not having any or only a limited relevance in other communities of practices. Secondly, some students seemed to have reached the conclusion that the potential of achieving legitimacy and meaningfulness was greater if they chose not to participate in PE. In fact, in some of the observed classes a social community was built around not participating. Students' deliberate choices not to participate seemed further reinforced by their experiences of nonparticipation not having any consequences and by the notion that PE was more like a break than a school subject. It seems reasonable that this typical notion of PE among students could partly be explained by the fact that grades and exams have not until recently been a practice in PE in Danish schools. While the use of assessment has been criticised in other studies on PE (Hay, 2005), it seems in this study that the lack of grades and exams could actually be contributing to students choosing not to participate in PE.

While this study agrees with others in relation to the importance of inquiring into students' multiple social categories, there also seem to be some nuances in the way inclusion and exclusion processes were expressed in this study compared to others. First, contrary to findings identified through our literature review, the ethnic minority background of many of the students we observed and interviewed did not seem to be decisive in whether or not they participated, either among girls or among boys. In the interviews, many of the students reacted without understanding our questions about how and whether the variation in students' ethnicity was influential in their PE-classes. Working with a very compound multi-ethnic group, ethnicity seemed to disappear. Secondly, the way in which sport and motor skills have been described as crucially important for students being deprived of legitimacy in PE did not seem as visible and humiliating in our case as described by, for example, Grimminger (2013) in her study of PE in lower grade and middle grade classes in Germany. Students generally seemed very appreciative of each other and to disapprove of jeers in PE. If students failed, this was normally not met by anger and if someone complained it was him/her rather than the one who had failed who was met by disapproval. The context-dependency of case studies could explain why the results of this study regarding certain aspects differ from those of other studies on inclusion and exclusion in PE. Thus, the location of the case in a Nordic physical education context and the composition of the student body are reflected in the values and practices of PE expressed by students and teachers in this study, in the interactions between students observed in this study, and in the conclusions drawn about students' experiences of participation and non-participation.

In our findings we have distinguished between those students excluded from participation in PE and those who actively choose not to participate. Based on our findings, we find this distinction important in relation to how we talk about students as passive victims or active agents. Furthermore, we find the distinction relevant to future practices in PE. In our interviews with teachers, they expressed a much greater concern over the challenge of including students choosing not to participate than including students who are excluded from participation; this was also supported by Scraton (1992) and Cockburn and Clarke (2002). While some didactical strategies aimed at ensuring the legitimacy of all students in PE, for example varying the methods of dividing classes into teams (see Grimminger, 2014b) and moderating the rules of competitive team games (see e.g. von Seelen, 2012), have already been suggested, only recently researchers have begun to discuss how to make PE more meaningful to students (Kirk \& MacDonald, 1998; Penney \& Chandler, 2000; Penney, Clarke, \& Kinchin, 2002; Kirk \& Kinchin, 2003; Penney, 2003). Reproducing and transforming other communities of practice known by students outside school has been argued to be one way of making PE more meaningful to students, for example by enabling students to transfer learning from PE to opportunities to do sports in their spare time (Kirk \& MacDonald, 1998). Some researchers have suggested Sports Education as one curriculum model, building on these principles (Kirk \& MacDonald, 1998; Siedentop, 1994). However, others have questioned the nature and extent of transfer achievable for students in this curriculum model and have suggested that connections to communities of practice other than that of sport should be sought (Penney \& Chandler, 2000; Penney et al., 2002). Furthermore, we agree with Penney and Chandler (2000) that connections of learning should not only be provided between PE and extra-curricular activities outside school, but also between learning in different units of $\mathrm{PE}$, and between learning in PE and other curriculum areas, seeking to make PE more meaningful to students in school. After our data collection ended, the PE curriculum in Denmark was changed in favour of (among other things) a more thematic approach to PE, which has been suggested as one way of pursuing connectedness and meaningfulness for PE (Penney \& Chandler, 2000). However, further studies are needed to develop strategies to enhance students' experiences of meaningfulness in PE and to empirically explore whether these strategies could include more of the students who choose not to participate in PE.

\section{Acknowledgments}

The authors would like to thank the PhD Council of Denmark for funding the research undertaken for this article. We thank the students and teachers of the case school for their willingness to participate in the study. Finally we thank the anonymous reviewers of the arti- 
cle for their competent and constructive comments and suggestions for the article.

\section{Conflict of Interests}

The authors declare no conflict of interests.

\section{References}

Alexander, T. (2001). Citizenship schools: A practical guide to education for citizenship and personal development. London: Campaign for learning.

Azzarito, L., \& Solomon, M. A. (2005). A reconceptualization of physical education: The intersection of gender/race/social class. Sport, Education and Society, 10(1), 25-47.

Carlson, T. B. (1995). We hate gym: Student alienation from physical education. Journal of Teaching in Physical Education, 14(4), 467-477.

Cockburn, C., \& Clarke, G. (2002). Everybody is looking at you! Girls negotiating the "femininity deficit" they incur in physical education. Women Studies International Forum, 25(6), 651-665.

Corbin, C. B. (2002). Physical activity for everyone: What every physical educator should know about promoting lifelong physical activity. Journal of Teaching in Physical Education, 21(2), 128-144.

Dagkas, S., \& Armour, K. (Eds.) (2012). Inclusion and exclusion through youth sport. New York: Routledge.

Dagkas, S., \& Benn, T. (2006). Young Muslim women's experiences of Islam and physical education in Greece and Britain: a comparative study. Sport, Education and Society, 11(1), 21-38.

Dagkas, S., Benn, T., \& Jawad, H. (2011). Multiple voices: improving participation of Muslim girls in physical education and school sport. Sport, Education and Society, 16(2), 223-239.

Dubois, A., \& Gadde, L. E. (2002). Systematic combining: An abductive approach to case research. Journal of Business Research, 55(7), 553-560.

Evans, J. (1989). Swinging from the crossbar: Equality and opportunity in the physical education curriculum. British Journal of Physical Education, 20(2), 84-87.

Evans, J., Lopez, S., Duncan, M., \& Evans, M. (1985). Some thoughts on the political and pedagogical implications of mixed sex groupings in the physical education curriculum. British Educational Research Journal, 13(1), 59-71.

Flintoff, A., \& Scraton, S. (2001). Stepping into active leisure? Young women's perceptions of active lifestyles and their experiences of school physical education. Sport, Education and Society, 6(1), 5-21

Flintoff, A., \& Scraton, S. (2006). Girls and physical education. In D. Kirk, D. MacDonald, \& M. O'Sullivan (ed.). The handbook of physical education (pp. 767783). London: SAGE.

Griffin, P. (1984). Girls' participation patterns in a mid- dle school team sports unit. Journal of Teaching in Physical Education, 4(1), 30-38.

Griffin, P. (1985). Boys' participation styles in a middle school team sport unit. Journal of Teaching in Physical Education, 4(2), 100-110.

Grimminger, E. (2013). Sport motor competencies and the experience of social recognition among peers in physical education: A video-based study. Physical Education and Sport Pedagogy, 18(5), 506-510.

Grimminger, E. (2014a). The correlation of recognition and non-recognition experiences in physical education with children's self-concept: Are there really gender differences? Journal of Physical Education and Sport, 14(2), 222-231.

Grimminger, E. (2014b). Getting into teams in physical education and exclusion processes among students. Pedagogies: An international Journal, 9(2), 155-171.

Hay, P. (2005). Making judgements: Student ability and assessment in physical education. Journal of Physical Education New Zealand, 38(1), 41-50.

Hay, P., \& MacDonald, D. (2010). Evidence for the social construction of ability in physical education. Sport, Education and Society, 15(1), 1-18.

Hills, L. (2007). Friendship, physicality, and physical education: An exploration of the social and embodied dynamics of girls' physical education experiences. Sport, Education and Society, 12(3), 317-336.

Kirk, D. (1994). Making the present strange? Sources of the current crisis in physical education. Discourse, 15(1), 46-63.

Kirk, D. (1999). Physical culture, physical education and relational analysis. Sport, Education and Society, 4(1), 63-73.

Kirk D., \& Kinchin, G. (2003). Situated learning as a theoretical framework for sport education. European Physical Education Review, 9(3), 221-235.

Kirk, D., \& Macdonald, D. (1998). Situated learning in physical education. Journal of Teaching in Physical Education, 17(3), 376-387.

Knez, K., MacDonald, D., \& Abbott, R. (2012). Challenging stereotypes: Muslim girls talk about physical activity, physical education and sport. Asia-Pacific Journal of Health, Sport and Physical Education, 3(2), 109-122.

Krueger, R. A. (1994). Focus group. A practical guide for applied research. Newbury Park: Sage.

Laub, T. B., \& Pilgaard, M. (2013). Danskernes motionsog sportsvaner 2011. Copenhagen: Idrættens Analyseinstitut.

Lave, J., \& Wenger, E. (1991). Situated learning: Legitimate peripheral participation. Cambridge: Cambridge University Press.

MacDonald, D., Pang, B., Knez, K., Nelson, A., \& McCuaig, L. (2012). The will for inclusion: bothering the inclusion/exclusion discourses of sport. In S. Dagkas \& K. Armour (Eds.), Inclusion and exclusion through youth sport (pp. 9-23). New York: Routledge. 
McGee, J. E., \& Hardman, K. (2012). Muslim schoolgirls' identity and participation in school-based physical education in England. SportLogia, 8(1), 49-71.

Merriam, S.B. (1988). Case study research in education: A qualitative approach. San Francisco: Jossey-Bass.

Morgan, D.L. (1996). Focus groups. Annual Review of Sociology, 22(1), 129-152

Munk, M., \& von Seelen, J. (2012). Status på Idrætsfaget 2011 (SPIF-11). Haderslev: KOSMOS.

O'Donovan, T. M. (2003). A changing culture? Interrogating the dynamics of peer affiliations over the course of a sport education season. European Physical Education Review, 9(3), 237-251.

Oliver, K. L., Hamzeh, M., \& McCaughtry, N. (2009). Girls can play games/las minas pueden jugar tambien: Co-creating a curriculum of possibilities with fifth-grade girls. Journal of Teaching in Physical Education, 28(1), 90-110.

Patton, M. Q. (1990). Qualitative research and evaluation methods. Beverly Hills, CA: Sage.

Penney, D. (2002). Equality, equity and inclusion in physical education and school sport. In A. Laker (Ed.), The sociology of sport and physical education: An introductory reader (pp. 110-128). London: Routledge.

Penney D. (2003). Sport education and situated learning: Problematizing the potential. European physical education review, 9(3), 301-308.

Penney, D., \& Chandler, T. (2000). Physical education: What future(s)? Sport, Education and Society, 5(1), 71-87.

Penney, D., \& Evans, J. (2002). "Talking gender". In D. Penney (Ed.), Gender and physical education: Contemporary issues and future directions (pp. 13-23). London: Routledge.

Penney, D., Clarke, G., \& Kinchin, G. (2002). Developing physical education as a "connective specialism": Is sport education the answer? Sport, Education and Society, 7(1), 55-64.

Portman, P. A. (1995a). Coping behaviors of low-skilled students in physical education: Avoid, announce, act out, and accept. Physical Educator, 52(1), 29-39.

Portman, P. A. (1995b). Who is having fun in physical education classes? Experiences of sixth-grade students in elementary and middle schools. Journal of Teaching in Physical Education, 14(4), 445-453.

Scraton, S. (1992). Shaping up to womanhood: Gender and girls' physical education. Buckingham: Open University Press.

Scraton, S. (1993). Equality, coeducation and physical education in secondary schooling. In J. Evans (Ed.), Equality, education and physical education (pp. 139153). London: Falmer Press.

Siedentop, D. (1994). Sport education: Quality PE through positive sport experiences. Champaign: Human Kinetics.

Stake, R. (1981). The art of case study research. Thousand Oaks, CA: Sage Publications.

Stidder, G., \& Hayes, S. (Eds.) (2013). Equity and inclusion in physical education and sport (2nd ed.). New York: Routledge.

Van der Mars, H. (2006). Time and learning in physical education. In D. Kirk, D. Macdonald, \& M. O'Sullivan (Eds), The handbook of physical education (pp. 191213). London: Sage.

Von Seelen, J. (2012). Praksis, Læring og kvalitet $i$ idrætstimerne. (Doctoral dissertation). Odense: Syddansk Universitet.

Wenger, E. (1998). Communities of practice: Learning, meaning, and identity. Cambridge: Cambridge University Press.

Williams, A., \& Bedward, J. (2002). Understanding girls' experience of physical education: relational analysis and situated learning. In P. Dawn (Ed.), Gender and physical education, contemporary issues and future directions (pp. 146-159). London: Routledge.

With-Nielsen, N., \& Pfister, G. (2011). Gender constructions and negotiations in physical education: Case studies. Sport, Education and Society, 16(5), 645-664.

\section{About the Authors}
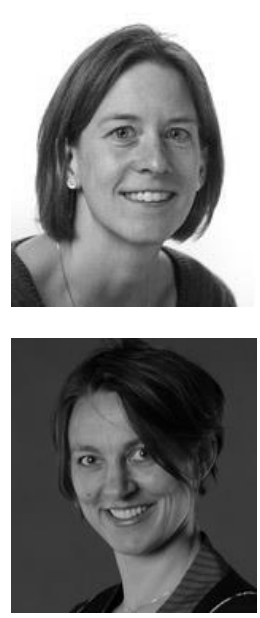

\section{Mette Munk}

Mette Munk is a PhD student in the Department of Public Health at the University of Aarhus in collaboration with the University College Syddanmark. Her earlier research has focused on the qualifications of Danish physical education teachers, the discrepancy between the curriculum and the actual content of physical education in Danish schools, and the introduction of grades and exams in physical education in Denmark. In her current research, she pays particular attention to teaching models aimed at promoting a more inclusive learning environment in physical education.

\section{Dr. Sine Agergaard}

Sine Agergaard is a social anthropologist and an associate professor in the Section of Sports Science at Aarhus University. Her research focus is on sport and migration, with particular attention to inclusion and exclusion processes within professional as well as recreational sports. Sine Agergaard has published a number of articles in peer-reviewed journals and contributed to and edited several books. She is currently the head of a Nordic collaborative research project, and the manager of the International Network for Research in Sports and Migration Issues. 